\section{DISCUSSION}

The present data replicate earlier studies (e.g., Ludvigson \& Sytsma, 1967) in demonstrating that strong response patterning is readily achieved when all $S s$ within a squad receive the same event, $R$ or $N$, on a given trial (Groups $N$ and NC). These data extend the previous work in two respects: (1) Response patterning appears stronger and extinction performance weaker when the reward schedule is a constant RRNNRRNN from day to day (Group NC vs N), and (2) no patterning appears when reward always follows an $N$ trial of the immediately-preceding $S$ and altemate preceding $S s$ receive the same event (Group R).

Regarding the odor hypothesis this latter finding indicates that even though the immediately-preceding event provides an unfailing odor cue for the current goal event no discrimination develops if on the second-most preceding (and generally every other) trial the odor cues are reversed.
The implication of this investigation for the methodology of runway studies is a relatively optimistic one: Although odor effects can readily produce a contamination of the effects of experimental treatments, they can be neutralized by a judicious sequence of goal events.

\section{REFERENCES}

LUDVIGSON, H. W., \& SYTSMA, D. The sweet smell of succes: Apparent double alternation in the rat. Psychonomic Science, 1967, 9, 283-284.

McHOSE, J. H., LUDVIGSON, H. W. Differential conditionin with nondifferential reinforcement. Pyychonomic Scieace, 1966, 6, $485-486$.

NOTE

1. This investigation was supported by U.S. Public Heath Research Grant No. MHI3314 from the National Institute of Mental Health.

\title{
Choice blas from unilateral cortical depression
}

\section{ERNEST G. GREENE ${ }^{l}$ and JOEL ADKINS, University of Oregon Eugene, Ore. 97403 \\ Spreading depression of one cortical hemisphere causes rats to choose the arm of a Y-maze that is ipsilateral to the depression. This choice bias is similar to the effects of unilateral brain lesion. The blas may reflect an asymmetry of perceptual or motor functions produced by the depression.}

There are two principle ways to functionally separate one cortical hemisphere from the other. One method is to cut the connections between the two halves of the brain, and thus produce a "split-brain" animal. In such an animal, the perceptions and memory processes of one hemisphere appear to be completely independent of the other (Sperry, 1964). The other technique is to disrupt temporarily the electrical activity of the cortex on one side by spreading depression. Bures \& Buresová (1960) have reported that memories for complex habits can be stored selectively in one hemisphere by training the animal with the other side depressed. The memory remains on one side unless the animal is given a few trials with both hemispheres undepressed, in which case the memory transfers to the other side as well (Russell \& Ochs, 1961; Ross \& Russell, 1964; Albert, 1966).

Buresová, Bures, \& Beran (1958) have reported that inherent motor dominance (handedness) can be disrupted by unilateral depression. When the cortex contralateral to the preferred hand is depressed, the rat will tend not to use that hand in reaching for food.

Koppman \& O'Kelly (1966) have reported that unilateral depression of cortical function produces a bias in the animal's choice behavior. They found that running speed and number of correct choices of the reinforced goal-arm are enhanced when that arm is on the same side as the cortical depression, but are impaired when the reward is in the arm contralateral to the depressed hemisphere. They suggest that a change in perceptual or motor dominance is responsible for the bias. Though that conclusion may be valid, it cannot be deduced unambiguously from their study. Their animals were trained in a learning task, and were rewarded for choosing one arm of the maze. One might argue that the choice bias could result from anomalies in memory or motivational processes. In fact, there was some reason to suspect that motivational incentive was a factor in determining the choice bias. Koppman (1963) had previously found that when shock was used as the reinforcer, the bias was contralateral to the depressed hemisphereopposite of the bias under food-motivated conditions.

The present research grew out of unpublished observations of choice bias produced by unilateral drug stimulation of cortex and hippocampus. The effects of those treatments could not be produced reliably, and there was reason to suspect that the effects were in fact due to spreading depression. In the present experiment, the unrewarded choices of animals with unilateral spreading depression of the cortex were examined for choice bias. The results complement the research of Koppman \& O'Kelly (1966) and help to clarify the nature of the bias.

\section{METHOD}

The Ss were 20 male albino rats purchased from Rush Laboratories, Beaverton, Oregon. They were 106-111 days old at the time of surgery.

Each $S$ was implanted with a cannula, which was used to inject solutions into the cortex. The cannula was constructed from two pieces of syringe needle, one fitting inside the other. The outer needle (shaft) was made of 21-gauge needle stock, and was cut to a length of $8 \mathrm{~mm}$. The inner needle (probe) was made from 27-gauge needle stock, and was cut slightly longer than the shaft. One end of the probe was crimped to function as a depth stop, and when the probe was seated in the shaft, their tips were flush. The probe could be removed with forceps, but it could not be removed by the $S$.

The operations were done stereotaxically under sodium pentobarbital anesthesia. The cannula was placed relative to bregma: $2.6 \mathrm{~mm}$ posterior, $2.0 \mathrm{~mm}$ to the right, and $3.0 \mathrm{~mm}$ deep. That depth coordinate places the cannula tip about $1 \mathrm{~mm}$ below the surface of the cortex. The cannula was fixed to the skull with bent-wire anchors and dental cement. Each $S$ was allowed at least 4 days of postoperative recovery before being tested.

The Ss were divided into groups of $10 \mathrm{Ss}$ each. In one group, $1 \mu \mathrm{l}$ of $10 \% \mathrm{KCl}$ was injected into the cortex, and in the other, buffered physiological saline solution was injected. A Sage syringe pump was calibrated to deliver this volume in a period of $3 \mathrm{sec}$. The solution was delivered from the syringe through a polyethylene tube to a special "injection probe." Before the $S$ was tested for choice bias, the regular cannula probe was removed from the shaft, the injection probe was inserted, and the solution was injected. 
One minute after the injection, each $S$ was given the first of five choices in the $Y$-maze. The animals had not been deprived of food or water, and no special reward was placed in the goal-arms. The $\mathrm{S}$ was allowed to enter an arm, and the gate was closed behind it. It was kept in the arm for $5 \mathrm{sec}$, and was then retumed to the startbox for the next trial. At least five trials were given to each $S$, though in some cases more trials were given.

\section{RESULTS}

The choices made by the Ss are shown in Table 1. The first five choices were scored for number of right turns, and the scores were compared using a $t$ test for the difference between means. The computed $t=3.41$ is significant at $p<.005$.

Subjects which had been treated with $\mathrm{KCl}$ tended to choose the right goal-arm (ipsilateral to the injection), and Ss injected with control saline tended to choose the left arm. Choice of the right arm by depressed Ss was significantly greater than would have been expected by chance $(t=2.75, p<.05)$. The bias of control Ss was not quite significant at $p<.05$ $(t=2.22)$, but their behavior may reflect a true bias to the left. Such a left bias might be due to the control procedure, or possibly to an inherent left bias among the population from which these animals were sampled.

The bias of $\mathrm{KCl}$-treated animals can easily be seen in their choice sequences. Some of the animals made a long series of right choices. For example, Ss 11, 16, and 14 chose the right arm 11,10 , and 8 times in a row, respectively. Only one saline injected animal showed similar perseverative behavior; $S 2$ chose the left arm four times in a row. Unfortunately, this $S$ was not given additional choice opportunities.

Aside from the turning bias shown by the depressed Ss, their behavior appeared quite normal. They responded normally to handling, and $\mathrm{ran}$ well in the maze. Their coordination was good, and there was no sign of any motor dysfunction.

\section{DISCUSSION}

The results of the present study confirm the report by Koppman \& O'Kelly (1966) that with unilateral depression of the cortex, choices are biased toward the depressed side. In the present study, animals tended to choose the arm of a $Y$-maze that was ipsilateral to the depression. The animals were not rewarded for a particular choice, and it seems unlikely that a change in motivational or memory processes produced the bias. Rather, the results support the suggestion by Koppman \& O'Kelly (1966) that unilateral depression produces a perceptual or motor dysfunction.

The effects of unilateral depression are similar to the reported effects of unilateral lesion of cortical areas. Kennard $\&$ Ectors (1938) reported that monkeys with unilateral lesion of frontal cortex circle to the ipsilateral side and tend to disregard objects appearing in the contralateral visual field. Denny-Brown \& Chambers (1958) reported that unilateral lesion of the posterior half of the parietal lobe of monkeys was followed by an "attention hemianopia" for the contralateral side. For example, the animals would not reach out and grasp

Table 1

Y-Maze Choices

\begin{tabular}{rlcl}
\hline S & Control Subjects & S & Depressed Subjects \\
\hline 1 & LRRLL & 11 & RRRRRRRRRRRL \\
2 & RLLLL & 12 & RRRRLRL \\
3 & RRRLL & 13 & RRRRRRL \\
4 & LLRLR & 14 & RLRRRRRRRRL \\
5 & LLRLR & 15 & RLLLRLLL \\
6 & LRLRL & 16 & RRRRRRRRRRL \\
7 & RRLRL & 17 & RRRLRRL \\
8 & LRLRL & 18 & RRLLL \\
9 & LLRLR & 19 & RRLLRLRRRL \\
10 & RLLRL & 20 & LLRLRL \\
\hline
\end{tabular}

an object approaching from that side. Removal of parietal cortex plus the precentral pyramidal fields caused a tendency to tum the head toward the side of the lesion. The monkey's head and eyes appeared to be attracted toward that side. After 1 week, the head-turning bias no longer occurred, but visual inattention to the contralateral side persisted. Similar deficit was found with unilateral lesion of the intraparietal area (Brodmann's Area 7).

Denny-Brown \& Chambers (1958) further report that humans with unilateral damage to parietal areas tend to ignore the side of their body contralateral to the damage. A patient may deny that the limbs on that side are his own, may disregard events taking place on that side, or act as though the events had occurred on the side ipsilateral to the lesion. It is especially interesting that these persons are often completely unaware of the abnormality, and may deny the existence of the dysfunction.

From these reports it is clear that lateralized perceptual dysfunctions may be produced by cortical lesions. However, Gazzaniga, Bogen, \& Sperry (1962) report that hemispheric dominance produces a similar deficit in a split-brain human. If the left (dominant) hemisphere is involved in some task, this person may be completely unaware of events on the left side of his body. When blindfolded, he is unable to say where he has been touched on the left side of the body, or describe the position of his own left hand. Perhaps the depression of one cortical hemisphere caused a similar lack of awareness by the animal of conditions and events on the side contralateral to the depression. A perceptual deficit of this kind could easily produce perseverative choices of one maze arm, while the other arm went unnoticed. If this were true, one might explain the discrepancy in choice bias found by Koppman (1963). He found that when shock was used as the reinforcer, animals chose the arm contralateral to the depressed hemisphere opposite of the bias seen when food reward or no reward is given. Perhaps in each case the animal is responding to the side which is salient in its awareness, avoiding it when it is afraid, and choosing it when positively motivated.

\section{REFERENCES}

ALBFRT, D. J. The effect of spreading depression on the consolidation of learning. Neuropsychologia, 1966, 4, 49-64.

BURES, J., \& BURESOVÁ, O. The use of Leao's spreading depression in the study of interhemispheric transfer of memory traces. Journal of Comparative \& Physiological Psychology, 1960, 53, 558-563.

BURESOVÁ, O., BURES, J., \& BERAN, V. A contribution to the problem of the "dominant" himisphere in rats. Physiologid Bohemoslovenica, 1958, 7, 29-37

DENNY-BROWN, D., \& CHAMBIRS, R, A. The parietal lohe and behavior. Research Publications. Association for Research in Nervous and Mental Diseases, 1958,36, 37-117

GAZZANIGA, M. S., BOGEN, J. F.. \& SPERRY, R. W. Some functional effects of sectioning the cerebral commissures in man. Proceedings of the National Academy of Science. 1962, 48, 1765-1769.

KENNARD, M., \& FCTORS. L. Forced circling in monkeys following lesions of the frontal lobes Journal of Neurophrsiology, 1938, 1 , 45-54.

KOPPMAN, J. W. Effect of uniluteral spreading depression and task difficulty on interhemispheric iransfer of avoidance learning. Unpublished doctoral dissertation, liniversity of Illinois, 1963.

KOPPMAN, J. W., \& O'KELLY, L. I. Unilateral cortical spreading depression: A determiner of hehavior at a choice point. Journal of Cumparative \& Physiological Psychology, 1966, 62, 237-242.

ROSS, R. B. \& RUSSELL, I. S. Lateralization and one-trial interhemispheric transfer of avoidance conditioning. Nature, 1964 , $204,909-910$.

RUSSELL, I. S., \& OCHS. S. One trial interhemispheric transter of a learning engra-7. Science. 1961, 133, 1077-1078.

SPERRY, R. W. The great cerebral commissure. Scientific American, $1964,210,42-52$

$$
\text { Ni) II: }
$$

1. Present address: Department if Pharmacology. (enter for Heahth

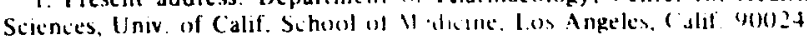

